\title{
Practising chaordic beauty: On embracing strangers in one inner city faith community
}

\begin{tabular}{|c|c|}
\hline \multicolumn{2}{|c|}{$\begin{array}{l}\text { Author: } \\
\text { Stephan de Beer }{ }^{1,2}\end{array}$} \\
\hline \multicolumn{2}{|c|}{$\begin{array}{l}\text { Affiliations: } \\
{ }^{1} \text { Centre for Contextual } \\
\text { Ministry, Faculty of Theology, } \\
\text { University of Pretoria, } \\
\text { South Africa }\end{array}$} \\
\hline \multicolumn{2}{|c|}{$\begin{array}{l}{ }^{2} \text { Department of Practical } \\
\text { Theology, University of } \\
\text { Pretoria, Faculty of Theology, } \\
\text { University of Pretoria, } \\
\text { South Africa }\end{array}$} \\
\hline \multicolumn{2}{|c|}{$\begin{array}{l}\text { Project leader: S.F. de Beer } \\
\text { Project number: } 86233689\end{array}$} \\
\hline \multicolumn{2}{|c|}{$\begin{array}{l}\text { Description: } \\
\text { This research is part of the } \\
\text { research project, 'Social } \\
\text { Justice and Reconciliation', } \\
\text { which is directed by Dr } \\
\text { Stephan de Beer, Director of } \\
\text { the Centre for Contextual } \\
\text { Ministry and member of the } \\
\text { Department of Practical } \\
\text { Theology, Faculty of Theology, } \\
\text { University of Pretoria. }\end{array}$} \\
\hline \multicolumn{2}{|c|}{$\begin{array}{l}\text { Corresponding author: } \\
\text { Stephan de Beer, } \\
\text { stephan.debeer@up.ac.za }\end{array}$} \\
\hline \multicolumn{2}{|c|}{$\begin{array}{l}\text { Dates: } \\
\text { Received: } 02 \text { June } 2016 \\
\text { Accepted: } 14 \text { Aug. } 2016 \\
\text { Published: } 18 \text { Nov. } 2016\end{array}$} \\
\hline \multicolumn{2}{|c|}{$\begin{array}{l}\text { How to cite this article: } \\
\text { De Beer, S., 2016, 'Practising } \\
\text { chaordic beauty: On } \\
\text { embracing strangers in one } \\
\text { inner city faith community', } \\
\text { HTS Teologiese Studies/ } \\
\text { Theological Studies 72(1), } \\
\text { a3523. http://dx.doi. } \\
\text { org/10.4102/hts.v72i1.3523 }\end{array}$} \\
\hline \multicolumn{2}{|c|}{$\begin{array}{l}\text { Copyright: } \\
\text { (C) 2016. The Authors. } \\
\text { Licensee: AOSIS. This work } \\
\text { is licensed under the } \\
\text { Creative Commons } \\
\text { Attribution License. }\end{array}$} \\
\hline Read online & \\
\hline 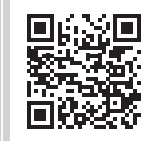 & $\begin{array}{l}\text { Scan this QR } \\
\text { code with your } \\
\text { smart phone or } \\
\text { mobile device } \\
\text { to read online. }\end{array}$ \\
\hline
\end{tabular}

In this article I read one inner city faith community - the Tshwane Leadership Foundation (TLF) - through the lenses of literature that reflects on chaordic organisations and chaordic leadership. I explore whether an emphasis on the management of diversity, which is widespread in organisational and ecclesial practices and languages, should not be replaced with a spirituality of vulnerable embrace, as I discover it in this specific faith community. It is a spirituality that combines an invitation and radical embrace of diversity, and a dance with chaos, with a posture of vulnerability and a vision of justice. I bring the reflections of community members in TLF on difference and diversity in their organisation, in conversation with scholars contemplating chaordic organisations and chaordic leadership. I then wonder whether their emphasis on embrace instead of management does not open up the possibility of retrieving and affirming the hidden beauties and potentialities mediated by diversity, which is, I suggest, to practise 'chaordic beauty'.

\section{Entering chaos - Is this not the story of life?}

One just has to enter the reception area of the Tshwane Leadership Foundation (TLF) ${ }^{1}$ on most days of the week, to be immediately invited, enchanted or intimidated by chaotic diversity.

Outside the main building of TLF a hand-painted banner welcomes guests with these words 'Welcoming strangers, welcoming Jesus'. It was painted during the first outbreak of xenophobic violence against foreign nationals in 2008. It identifies Jesus in and with the stranger, which is a central point of departure theologically and organisationally for TLF: meeting Jesus in the stranger. Inside the reception area, very visible on the wall above the piano, hangs the Eichenberg painting of 'Jesus in the breadline', a homeless stranger among other homeless strangers.

Perhaps these two pictures, together with the enchanting, for some perhaps disturbing, chaos of the reception area, bear resemblance to the way in which the TLF seems to work with issues of diversity.

In this article I will reflect on the ways in which TLF (Tshwane Leadership Foundation 2016), as an intentional Christian faith community in the inner city of Pretoria, seeks to deal with diversity. One encounters a remarkable diversity in TLF and its different communities: to the uninitiated eye, on the best of days, seemingly chaotic. In conversations however there is a complete absence of any language about 'managing diversity'. What is surfacing clearer, and in contrast, is a simple language, retrieving theological or spiritual categories, very much away from managerial, technocratic or bureaucratic jargon. It is a language laden with images such as embrace, warm hospitality, welcome, inclusion, a table of abundance, humanity, image of God, loving our neighbour and one community.

This corresponds with Ascough's reading (2002:27) of Paul, suggesting that in Paul's letters to the Corinthians and Galatians, '(r)ather than lay down a set of rules he advocated a few simple concepts (mutual love, mutual slavery, Spirit guidance) and expected that from these the communities would grow and flourish'.

What I will explore is the possibility of dealing with diversity differently in faith communities. In subverting organisational and ecclesial practices and languages, that 'other' the stranger in attempts to 'manage' diversity, TLF seems to practise a simple embrace and celebration of both diversity and the 'chaos' it brings. In doing so TLF is performing a dance, out of control, and into 1.The TLF is an ecumenical community organisation, based in the inner city of Pretoria or Tshwane, and committed to urban transformation
that is socially inclusive. Started in 1993, it developed a range of responses and local base communities in solidarity with some of the city's most vulnerable people. 
a 'new order', which I would like to refer to as chaordic beauty. In this regard I would align this paper with recent literature reflecting on chaordic organisations and chaordic leadership.

\section{'Loss' and 'embrace': Who and what is TLF?}

The extent of diversity in TLF, and the chaos of it, could be overbearing at first, for those used to homogeneity, suburban order or sophisticated managerial and institutional infrastructure. It could also be offensive, theologically or socially, if one opts for a theory of managed diversity which neatly secures inclusion on our own terms, within boundaries and criteria carefully selected.

It is told of a social worker, a woman of faith, who intended to work as a volunteer with the TLF, that she attended a workshop of gender and sexuality with them. Afterwards she said that the diversity of this community is amazing, but for her the diversity was also 'too much'. So she decided not to work with them as a volunteer. She was especially concerned with the space made for people from different sexual orientations than her own, or what she held as the correct 'Christian' understanding of what 'appropriate' sexual orientation was.

Diversity has a way to confront one, not just with 'the other' in the first place, but even more significantly with oneself. Our theological convictions, personal biases, prejudices and preferences and ecclesial habits are all immediately assessed and articulated, in the face of 'the other', or the one who is different from me.

When faced with unsettling diversity, it could for some mean an experience of feeling lost - loss of certainties, loss of security, challenged identity, challenged sense of the meaning of Christian community, even of faith itself, and - even - a sense that one's construct of God might be at risk.

Perhaps the way in which TLF struggles with contextualising the gospel on a daily basis in the inner city is part of the way in which they seek to deal with diversity. The commitment of TLF for the past 23 years has been to create a presence with some of the city's most vulnerable people, in ways that would affirm dignity, foster respectful community and make space for people being empowered into discovering and living the image of God in them (cf. De Beer 2008; De Beer \& De Beer 2002; Hillis 2014).

The call of Jesus to lose our lives if we want to gain it is perhaps also how TLF seeks to negotiate identity and diversity in their context. In being lost, or willing to let go - at least of constructs that are too certain and too fixed - it seems as if they become able to construct a different identity or identities, together, not at the expense of the diversity, but in embrace and celebration of it. One person reflected on this speaking of a new 'TLF culture', perhaps capturing something of the alternative, almost counter-cultural community it seeks to foster.
It resembles something of what Volf (1996) describes in his important book Exclusion and Embrace:

The will to give ourselves to others and 'welcome' them, to readjust our identities to make space for them, is prior to any judgement about others, except that of identifying them in their humanity. The will to embrace precedes any 'truth' about others and any construction of their 'justice'. This will is absolutely indiscriminate and strictly immutable; it transcends the moral mapping of the social world into 'good' and 'evil'. (p. 29)

\section{Reflections on life together}

In March-April of 2016 I facilitated a focus group in which nine community members of TLF participated. The participants included a social worker in one of their programmes, a social work intern, an event organiser, a person working in the human resources office, a person doing an internship in an economic empowerment programme of TLF and two European students - one from Germany and one from the Netherlands. In addition the leader of the organisation, Wilna de Beer, and a member of the management team, Joel Mayephu, responded in writing to specific questions I posed, similar to the questions discussed in the focus group. ${ }^{2}$ The group I engaged with varied in terms of age, race, ethnicity, language, gender and nationality. They also come from different Christian faith traditions.

In asking them to describe or articulate in words how TLF dealt with diversity, or how they live together, different perspectives were shared. One person said that TLF 'accepts and celebrates' diversity. The group felt that they saw evidence of that in their devotional times, in how management meetings are made up of very different people and yet, every person in the group was allowed in their diversity 'to shine'. Another person said: 'I feel welcomed at TLF, something I have never experienced; it is nice; everyone is friendly ...'.

Someone underscored the acceptance and celebration of diversity even more, suggesting that to understand how well a community deals with diversity one must look at is weakest link. She then continued to say that instead of management treating some people in hierarchical or exclusive ways, the management team in TLF worked hard to maintain diversity by ensuring 'that no one is getting left out'. It works deliberately to undo hierarchical structures. Searcy and Hall (2000), in an interview with Hock, capture it like this:

In the chaordic age, leadership will be enormously distributive. The old idea of thinking of leaders as superior people at the top dominating inferior people at the bottom will change. Everyone will have to simultaneously lead and follow. (n.p)

In the focus group it was also suggested that TLF was 'working hard against stigma' or stigmatising some people or some groups. Another person said it differently, emphasising the way in which TLF

2.The participants in the focus group are described in the text I did not use the names in the interest of confidentiality. The organisational leader, or CEO, is Wiln de Beer. She responded to interview questions in writing on 2 May 2016. A fellow member of the management team, Joel Mayephu, coordinating a community centre in the inner city neighbourhood of Salvokop as well as TLF's advocacy activities, also responded to interview questions in writing on 2 May 2016. 
tries to give different communities a sense of belonging; broken people a place called home where they can rebuilt their lives; people going through the same things are welcomed, taken in, loved and accepted the way you are, mostly.

I enquired on why the person qualified her powerful description with 'mostly' but she could not explain.

A European intern, who has already worked at TLF for 1 year, mentioned how she walked into TLF on the first day and people already knew her name, making her feel that people were 'interested in me'. Her sense, after working in TLF for just a couple of weeks, was that people knew each other in the community.

Someone else in the group mentioned how TLF offered empowering spaces, assisting vulnerable people, who are a central part of the community, to develop their resumes and to look for jobs.

The group referred to experiences they had in other service organisations where people who were vulnerable 'are helped but not embraced'. The notion of 'embrace' seems to be central, and 'working' at TLF, the group felt, was more than a job but indeed something of a call or vocation. As one participant said: 'In TLF everyone does more than what they are supposed to do', and she concluded that it was 'awesome'. Dee Hock (1999) probably had that in mind when he wrote:

The organisation of the future will be the embodiment of community based on shared purpose calling to the higher aspirations of people. (p. 6)

In many organisations a professional distance is created whilst a posture of 'embrace' subverts conventional hierarchies or client-expert relationships and rather invites a deep sense of mutuality in sharing and participation. During the course of the focus group a participant for example mentioned how a person who lived on the street, and accessed services in one of the TLF programmes, was now being employed by TLF. It seemed as if the whole group celebrated this fact. Embrace, at least purposefully sought, is practised not just as a gimmick but as a way of life and even evident in the processes of employing new staff.

Perhaps at this point it makes sense to return briefly to 'chaos' as this was never used as a term by any participant in the focus groups or either of the leaders I engaged with. I use the term deliberately in reflecting on what I found, and then in the way Ascough (2002) reflects on it, with reference to others:

The 'chaos' aspect of chaos theory is not understood as synonymous with confusion, disarray, and pandemonium. (p. 22)

Ascough then refers to Tetenbaum (1998:24) who describes chaos as 'a complex, unpredictable, and orderly disorder in which patterns of behaviour unfold in irregular but similar forms'.

\section{A community of strangers: Who are the people in TLF?}

The community of TLF is a diverse community. In asking the focus group to describe the community their sense was that it became 'home for everyone', that it 'does not discriminate due to colour, age, gender, culture' and that it treated everyone with the same respect.

It became clear from conversations with community members in TLF that their emphasis was not on 'managing diversity' but on 'embracing diversity'. This means a completely different starting point, seeing diversity not as a problem or challenge to be managed, but inviting diversity instead as a gift. The leader of the organisation, Wilna de Beer (2016), explained it in this way:

TLF embraces diversity in its approach. It creates space for everyone at the table. People from a diverse range of cultures, races and denominations come together and build community with each other. There is openness to hear everyone's voice and to engage in real dialogue. (n.p.)

The community of TLF is made up of younger and older people, South Africans and foreign nationals from the continent and Europe, black, white, Indian and coloured South Africans, as well as people speaking different mother tongues, including Sotho, Pedi, Zulu, Xhosa, Tsonga, Afrikaans, German, Shona, French and Lingala.

It is diverse in terms of the multidisciplinary nature of the personnel, representing people coming from different professional backgrounds, as well as lay people without formal qualifications, sharing the vision and commitments of the organisation. Although most people in the organisation would identify themselves as practising Christians, they also come from a vast diversity of Christian denominations.

In what was described in conversations the issue of economic differentiation was not pronounced, partly perhaps because of the overt option for the poor practised in and by TLF. This is probably central to its vision as an organisation - to create shared tables where the poor and most vulnerable of the city can be seated as equal participants.

This does not mean that all members of the community are necessarily poor. The majority of community members and staff come from poor backgrounds and only a few come from lower-middle or middle-income backgrounds. In addition to 73 full-time staff members (56 women, 17 men; 64 black, 7 white, 1 Indian, 1 coloured), TLF also hosts 22 local and 12 international interns or volunteers on an annual basis. The international volunteers come from the global North and therefore obviously from a different economic background to the majority of the local community members. They are deeply committed to the lifestyle of TLF when in South Africa, and most of them continue to be in solidarity with TLF upon returning to (mostly) Germany, often continuing to serve in similar capacities than in South Africa. 
What is remarkable in TLF is the way in which the salary differentiation of staff is being capped so that the lowest earning staff member and the highest earning staff member will be in a 1:8 ratio to each other, seeking to address the gross disparities usually reflected in most organisations.

One of the focus group members, a Zulu-speaking black woman, related her experiences of going to predominantly white Afrikaans primary and high schools where she was made to feel outside. She spoke about being 'damaged' and 'belittled' in school. In TLF, she said, 'I felt for the first time equal ... white people are actually cool'. She said that she felt at home, she felt loved and, although her self-esteem was lost in school, she now had a growing confidence and self-esteem.

\section{Race}

An intern who was from Zimbabwe said: 'When I am here I am always made to feel that I am part of them'. She spoke about how she never felt excluded.

De Beer (2016) indicates an understanding of the structural nature of racism when she reflected on how TLF dealt with issues of race, both structurally and dialogically, but also celebratory:

TLF deals with racial difference structurally, to ensure fair representation at all levels. It also plans specific moments where dialogue is invited around the issue. During Heritage month the team celebrates different cultures and discusses aspects of it. (n.p.)

Another community member who plays a leading role in the community and in the city, Joel Mayephu (2016), reflected on the issue of race by suggesting that in TLF they were 'openly confronting and discouraging racial (racist?) language, attitudes and insinuations' and they ensured that 'policies are in place for guidance' to deal with racial difference or with related grievances.

Unfortunately I have not been able to probe further on this occasion, to get a sense of how the community reflects on issues of blackness and whiteness, not just in their own community but also in how it gets expressed and how it continues to shape the urban context in which they serve, as well as the vulnerable communities who are often systematically excluded from mainstream society.

\section{Gender}

In asking the focus group how they understood issues of gender to be dealt with in TLF, different responses were shared. One participant said that her understanding of gender was heavily influenced by being a feminist and stressed the ways in which patriarchal constructs systematically excluded women. In TLF, however, she sensed an equal opportunity for women to work themselves up and found this to be supported by the fact that the organisation was led by a woman.
The organisation's special focus on women and women's abuse also stressed and informed their gender commitment. The group felt that one of the areas in which TLF particularly does well in relation to diversity was the way in which spaces were created for the empowerment of women.

Another participant felt that one could not focus on women and not on men too. She said,'Men are also being oppressed and also being vulnerable'. Gender and victim empowerment workshops dealt with women and men, as well as the realities of Lesbian, Gay, Bisexual, Transgender and Intersexed (LGBTI) groups, confronting patriarchal constructs and helping people to construct alternative imaginaries. De Beer (2016) stressed that:

TLF has embarked on a process of mainstreaming gender, including developing a gender policy and programme. Workshops and campaigns are planned and implemented with staff and community members, to raise gender awareness and develop capacity to deal with gender issues. (n.p.)

This was echoed by Mayephu (2016) who also emphasised the importance of 'learning and unlearning any culture that seems to be a violation ...', emphasising the image of God in all humans.

In terms of sexual orientation and the way in which TLF related to individuals self-identifying with the LGBTI group, participants in the focus group said that they never saw anybody from this group being discriminated against in TLF. Some members actually singled out the way in which LGBTI people were embraced in TLF, as one of the outstanding features of how it dealt with diversity. This was especially the case in a context where LGBTI people are still killed in some communities, which is particularly true of lesbian women in some townships, and in some cases such behaviour is even encouraged by pastors of churches.

Individual participants did mention hearing some negative comments from individual community members of TLF behind closed doors, but then stressed that these were isolated cases and definitely not supported by any TLF policy. Mayephu (2016) echoed this, stating that TLF did not discriminate against any person according to sexual orientation, but mentioned that it was still an issue for many individual staff members. He said that community interactions such as devotional times and other spaces were used to create and encourage openness, respect and the embrace of everyone without judgement or prejudice. Although some participants of the focus group thought that TLF did not yet speak openly about LGBTI issues in the community, the leader of the community asserted that it embraced 'all gender identities and actively include those who are marginalised due to their specific orientation'. This is probably demonstrated in the fact that a number of staff members self-identify as LGBTI. In the current environment in South Africa in which faith communities seem to deal with issues of sexual orientation in very ambivalent, unclear and non-committal ways, the embrace of people who are 
marginalised based on sexual orientation might offer a small but indeed freeing oasis to some.

\section{Religious and denominational diversity}

It was interesting that the question about religious and denominational diversity presented the most diverse reflections from participants in the focus group, the leader of the community and a member of the management team. In the focus groups people held that it is clear that TLF was a Christian organisation. One participant felt that 'maybe we do not offer the space for people from other religious beliefs'. More than one participant mentioned that they were asked what they believed in, in their job interviews. This was not necessarily mentioned as negative or discriminatory but simply stated factually.

The group thought that beneficiaries might feel oppressed, mentioning issues such as Halaal food not being available for people in residential programmes and 'we focus on our religion and not on theirs'. This particular conversation ended with a question about whether there was 'enough awareness about people from other religious to treat them with respect'.

\section{De Beer (2016) stated that}

(e)verybody has a right to practice their faith in whichever way they prefer. TLF gives the guidelines in terms of discerning what is right and good, but does not interfere with people's religious practices. (n.p.)

This was not further discussed and whether 'what is right and good' referred to Christian practices narrowly or religion generally was not clear. From the context of the statement it was assumed that it referred to religion in general.

Mayephu (2016) offered this perspective:

TLF perceives any religion as part of a journey towards or with God ... We do not discriminate against any religion or denomination but discourage any attitude, language, and actions that prove to be discriminative and judgemental. (n.p)

\section{The stranger}

The opening paragraph of this article possibly captures the essence of TLF's 'theology of strangers' identifying the stranger with Jesus and Jesus with the stranger. One can perhaps say it is a community set up for the stranger or the other, or, even, that it is a community of strangers itself. In many ways every person reflecting on the questions I posed are strangers, in one way or the other - either being part of a small white minority in the inner city, living with a disability, having come new into the community as community members ('beneficiaries' of support), interns, volunteers or new staff.

In the focus group it was stated that strangers 'are welcomed, reached out to' and offered 'coffee and tea'. One person said, 'people feel comfortable'. It was mentioned how newcomers would introduce themselves on Friday mornings in the community devotional times, being welcomed and clapped for.

Someone else emphasised how strangers are welcomed and immediately treated as part of our community since they already occupy our community space. We, through hospitality, create a sense of respect and hope to strangers who respect our community space, hopeless or helpless.

This applied to both local people, people coming from the streets, but also ways in which international student interns were welcomed and integrated into the community, from the onset.

In this reflection two striking postures are evident: an emphasis on hospitality as well as ownership - people are 'immediately treated as part of our community' and can make a contribution as equal members in the community from entering the community.

De Beer (2016) offered a simple but powerful summary on asking how strangers are treated in the community. She said they were '(e)mbraced and included with warm hospitality'. Embrace, inclusion (and ownership) and hospitality are the threefold approach TLF wants to adopt in welcoming strangers.

\section{Is anyone excluded?}

Considering the prior reflections, it obviously begs the question: is anyone excluded? In the focus group participants felt that the only people who were excluded were 'people who want to be excluded'. They referred to people who were 'extremely narrow minded', disqualifying themselves from being part of the community, or people 'who are insisting on making the same mistake', for example staff with drinking problems who then affect the community.

In a separate response Mayephu (2016) remarked that 'all and sundry are welcome in TLF'. He then qualified this by saying that 'only those who continuously violate and pose danger to our community are restrained until fully restored or showing signs of being restored'.

On the question of who was excluded in or by TLF, the response given was consistently not on the basis of class, race, gender, religious or denominational affiliation or any other category, but in terms of the choices individuals make which might either build or indeed violate the community and the rest of its members, thereby excluding themselves.

\section{Chaordic organisations: Out of control and into order}

The way in which chaordic is described is that it is a space, organisation or system that exists between order and chaos, dominated neither by order nor chaos, simultaneously holding both order and chaos in a harmonious and mutually complementary manner (cf. Hock1999, n.d.). 
First coined by Dee Hock (1999), former CEO of VISA, it was an attempt by him to articulate the organisational form that emerged in VISA, characterised by the distribution of governance, power and functions; the self-organising nature of its system; the blend of competition and collaboration; flexible yet durable organisational structures; and cooperative and equitable ownership.

He could not find a known term to describe the organisation that emerged out of the innovations discovered and practised in VISA, now being simultaneously chaotic and orderly, and thus coined the term chaordic. Over time a body of literature developed that reflects on the emergence of the so-called chaordic organisations. This is also an expression of chaos theory and describe in this way by Ascough (2002:xxx):

In contrast to a (Newtonian) model in which structure is imposed on an organisation from above, chaos theory is a biological model that sees an organisation as a living, self-organising web of relationships. (p. 21)

Chaordic organisations need chaordic leaders to provide appropriate guidance and accompaniment of such organisations. Based on Hock's original idea, theories and an understanding of chaordic organisations and chaordic leadership were further developed by people such as Wheatley (2006, 2007a, 2007b), Hjalmarson (2013), Motumura (n.d.) and others.

In a real sense chaordic organisations offered innovative alternatives to the kind of organisations we face on a daily basis, from universities and schools, to churches, non-profit organisations, government institutions and private sector companies. Motumura (n.d.) asks these poignant questions of organisational structures generally, as we have come to know them today:

How natural are the organisational structures with which we attempt to order our social lives? Put differently, the question is even more to the point: how unnatural, artificial, and forced are these structures? To what degree does this unnaturalness end up significantly compromising the effectiveness of organisations and affecting motivation? To what degree do our attempts to 'create order' or 'guarantee order and prevent chaos' obstruct the fullest expression of the human spirit? To what degree do mechanical structures (that presuppose that an organisation is a machine and not a living organism) box people in, fragmenting relations, putting walls between people, and limiting the actions and the greater purposes of business and governmental organisations? To what degree in schools and universities is the development of children and young people 'unnatural' and below their full potential due to archaic, limited, and ineffective organisational structures? (n.p)

Motumura (n.d.) suggests that the organisations that we know are unnatural in being hell-bent on 'managing' chaos, curbing organic expression, fragmenting diversity and quenching the spirit of what an organisation potentially could become, or is meant to be.

In reflecting on the ways in which TLF deals with diversity, inviting and embracing chaos and uncertainty on a daily basis, the characteristics described as that of a chaordic organisation were very evident. The ways in which it invites often 'lost' people to journey together into 'lostness', whilst being welcomed, embraced and held, and the ways in which the community collectively negotiate diversity, extending shared ownership and mutuality, adapting organisational structure continuously in response to contextual and organisational change and expressing a celebration of both chaos and diversity, suggest an alternative way of being to those of organisations which Motumura critiques. In response to ever-changing surrounding and internal contexts, TLF is adapting its organisational structure continuously. Ascough (2002:28) insists that this was Jesus' call to the church as an organisation: 'to be fluid, constantly redefining itself according to its current contexts. Chaotic? No! Rather it should be chaordic, that is, self-organising, seeking out its own optional solution to its current environment'.

Leadership in TLF also reflects such chaordic characteristics, yet not without tensions. When chaordic organisations collaborate with technocratic or managerialist organisations, they are bound to clash on important essentials. If both organisations are faith-driven and committed to the same greater good of the local urban neighbourhoods in which they serve, such tensions cannot simply be dismissed. It too needs to be creatively negotiated, discerned and, possibly, even embraced. In reflecting on Paul's leadership style, Ascough (2002:27) felt that 'Paul was content, even in the face of adversaries and rejection, to allow chaos in community, so that indigenous order might arise'. In that sense TLF and Paul both seem to have embraced what contemporary theorists would speak of as chaordicorganisational leadership.

Also, the very presence of conflict or creative tension is actually 'by definition' what chaordic organisations are (Tetenbaum 1998:28). Tetenbaum says 'the very tension that produces conflict also produces genuine creative, fruitful ideas'. Inviting chaos by definition means inviting difference and thereby possibly contesting voices and contestation that, when held creatively, can birth 'genuine creative, fruitful ideas'.

\section{Chaordic leadership: A dance - Out of control and into order}

Hjalmarson (2013:1)reflects on the crisis of the church as a crisis of leadership: 'The crisis we see is a crisis in leadership, because leaders are often the first to resist change, fearing loss of position or influence'. Hjalmarson (2013:1) reckons that the crisis is at the same time 'an opportunity to rediscover the vocation of the church as an authentic community, a living priesthood, a missional people in a foreign land'. It is an invitation and a challenge to replace hierarchical forms of leadership with more egalitarian leadership models. Such a shift, which to him has become imperative, requires a 'move from leadership cults, to leadership cultures'. Hjalmarson then borrows the concept of chaordic leadership as a metaphor for the new kind of leadership that the church is requiring today. 
Margaret Wheatley (2007) captures the problem with organisations and organisational leadership well when she writes:

Western practices attempt to dominate life; we want life to comply with human needs rather than working as partners. This disregard for life's dynamics is alarmingly evident in today's organisations. Leaders use control and imposition rather than self-organising processes. They react to uncertainty and chaos by tightening already feeble controls, rather than engaging our best capacities in the dance. (n.p)

Hjalmarson (2013) develops Wheatley's analogy of the dance further with reference to the Trinity:

The analogy of dance reminds us that the Trinity is also a model for leadership: mutuality, and participation. The 'best capacities'of people are engaged when they participate: when they have a voice, when they are valued as partners, and when they see that their work has meaning. These qualities of participation can help us to a new practice of leadership based on the nature of the Body of Christ. (p. 2)

Leadership as dance suggests not control in a rigid sense but allowing ourselves to be out of control, moving organically, finding order together in our dynamic and synchronised movement. Hjalmarson (2013:4) speaks of how control and certainty are overrated (western) values not compatible with the values of 'faith, dependence on the movement of the Spirit, a dynamics which is never in the control of the church'.

In chaordic organisations control and certainty are replaced with chaos and connections (cf. Hjalmarson 2013:4-6). To the foreign eye it might be seen as sheer chaos but once inside such a movement it becomes clear that different parts are actually becoming chaordically connected. It is indeed an out of control dance, dancing into order, in a way that resembles chaordic beauty (cf. Hock n.d.).

If the ultimate goal is a deep sense of community instead of stringent controls, or a broadly owned leadership culture instead of only good individual leaders, the characteristics of chaordic leadership need to be invited and fostered as it allows for 'a community in mission' which is 'a new vision of leadership’ altogether (Hjalmarson 2013:5).

In such a new leadership paradigm there is a rather radical shift away from hierarchical leadership to what Hjalmarson (2013:6) calls 'distributed leadership: a functional flat priesthood in the world'. In the language discovered in conversations with members of the TLF community it seems to assert a kind of leadership or community that embodies embrace; perhaps one can even speak of leadership as embrace, subverting hierarchical forms of leadership that divide and rule. Strong emphasis is placed on shared or communal leadership in TLF, moving beyond a narrow emphasis on individual leadership or hierarchical leadership structures.

It is required of such leaders to hold in creative tension 'intimate connection (community)', 'comfort with process and paradox' whilst 'working with the unseen elements of growth' (cf. Hjalmarson 2013:6). Chaordic leadership is comfortable with process, paradox, chaos and uncertainty. It is a way of leadership that live and dance with the Spirit, into and with paradox and chaos, as a community of participation and mutuality.

Martoia (quoted by Hjalmarson 2013:1) suggests as a challenge for leaders in the church today the fact that there is a 'lack of maps' and 'few cartographers' that could guide faith communities in and into unknown territories. Chaordic leadership seems to be able to make sense of uncharted territory, not being reliant on orderly certainties. When TLF started in 1993 it was 1 year before the political transition in South Africa and within 5-6 years from being started the environment in which TLF planted itself changed completely, both demographically and racially. There were indeed no maps and no cartographers; it was, in the words of Wheatley (2007), the 'unplanned organisation'. They had to chart their own journey and co-construct new maps. What is telling is that their origins was in anticipation to the complete transition that was about to come, dancing it in, so to speak. It had to find its own dance within the context: a dance of immersion, action, reflection, discernment, participation and mutuality, whilst finding many different interlocutors as dance partners along the way. And still today, the uncharted territories of dealing with homelessness and migration, vulnerable girl children or contested urban spaces require new kinds of leadership.

\section{A chaordic spirituality? Embracing vulnerability}

Can one speak of a chaordic spirituality? If chaordic organisations require chaordic leaders, then one can perhaps also conclude that, in faith-based communities, what will sustain the unfolding chaordic beauty would be a chaordic spirituality, embracing chaos and vulnerability.

De Beer (2016) was using four terms to describe diversity in TLF and how it is dealt with: inclusion, vulnerability, community and dialogue. This was further elaborated on by another community member, suggesting that in TLF 'diversity is embraced with consciousness of the organisation's vulnerability in dealing with the challenges diversity poses'. It not only seeks to embrace vulnerable people, but seeks to do so from an embrace of its own vulnerability as an organisation.

It is probably a spirituality of imperfection (cf. Kurtz \& Ketcham 1993) that seeks to find Jesus in the chaos, embracing liminality, discerning the Spirit in diversity and dancing with God into a 'new order'. It is a spirituality that finds and celebrates chaordic beauty together: dancing in disciplined ways and intentional spaces with chaos, out of control, and into order (cf. Hock n.d.). Traces of a chaordic spirituality can be found in the languages, practices and spaces cultivated in the community. 
It is characterised by great fluidity and constant change, and yet, within that, sustaining specific spiritual disciplines to 'hold' the dance in and through chaos and into order.

Some of that was indeed articulated in the focus group and individual responses to questions asked.

\section{Languages}

In terms of the language used, people I entered into conversation with used certain images or metaphors to describe TLFs theological perspective on diversity. It tends to be narrative and metaphorical language instead of clinical doctrinal language.

'Everyone is in the image of God', 'love your neighbour', a 'table of abundance' and 'one community' were some of the images that people retrieved in reflecting on how TLF considered diversity theologically. These are not merely clinical images but seem to be the images evoking embrace, informing community and retrieved continuously as reminders of who they want to be together.

The names of different projects and buildings also captured something of the vision behind projects and were often based in the values of the community. The community with young girl children who are vulnerable is for example named Lerato House ('lerato' is the Sotho word meaning 'love'). Other names have similar connotations and rather than seeing this as soft names, it denotes a tenacious resolve such as described by Wheatley (1992:39): 'Love in organisations, then is the most potent source of power we have available'.

Someone mentioned the logo of TLF, which is a vulnerablelooking person sitting in front of the cross and against the cityscape, as well as the banner on the front window, welcoming strangers, as well as other paintings or art work on the walls of TLF, as descriptive of its imaginary regarding issues of diversity and 'the other'. Even the vision in the Book of Revelation celebrating every nation, tribe, people and language, being in the presence of the Lamb, is retrieved as normative for a faith community seeking to embody the alternative values of Jesus. One response, from Mayephu (2016), held that Biblical as well as constitutional principles encouraged the embrace of diversity without violation of other people's rights. TLF sought to walk the tightrope in this regard.

\section{Practices and spaces}

On enquiring whether there were specific spaces created in which one could see how TLF sought to deal with diversity or difference, people spontaneously concurred with each other that this was to be seen 'every day, all the time' and 'at every devotion'. Entering chaos, embracing diversity and celebrating community are not a 'managed' affair for specific committees but become ordinary life together. Ascough (2002:29) says it is the relational Spirit that makes space 'within which the relationships develop chaordically'. Ascough is probably right!
The devotional times on Friday is a space, now honoured for 23 years, in which the community deliberately opens itself up to difference, and in which many diverse voices are encouraged to participate. In addition staff orientations, two annual retreats, monthly community celebrations and celebrating Holy Communion together are all important practices and spaces in which diversity is embraced, celebrated and cultivated.

There are also special events such as the annual Feast of the Clowns (2016), a community festival that celebrates the city, God in the city and the diversity of the city, founded by TLF in 2000 and becoming the largest community festival in the City of Tshwane. It has become a celebration of diversity in vulnerability since it's inception.

In considering the deliberate subversion of hierarchical leadership and the flat structures of the organisation, as well as the kinds of relational spaces and practices that seem to be what keeps TLF together as a community, as well as their intentional option for the poor and stranger, this reflection of Ascough (2002) came to mind:

It is not the intellect (what you know) but the community good (what is best for others) that should govern action. (p. 26)

And in doing the dance together, there seems to be an organic emergence of intuitive knowledge creatively woven together with an orthopraxy - actions that are right and best and in the interest of others - without romanticising the daily struggle for life amidst death in a community such as TLF.

\section{Naming prejudice}

I explored with the focus group and others how prejudice of different sorts was dealt with in the community. One person said 'by exposing and confronting such prejudice through educative engagement' that involved a constructive process of building understanding and consciousness regarding prejudice, its effects and possible alternative ways of engagement.

The group discussed this at length describing how modelling also contributed to naming and dealing with own prejudice. One would see other people dealing with diversity, racism, sexism and so forth, in an alternative (counter-cultural) way, be motivated by the exampled and over time socialised into practising an alternative way.

A caution was raised, however, in that some people who thrive on survival instinct might argue in themselves that 'in Rome we do as it is done in Rome', which might mean false adaptation to chaos and diversity, adopting a certain lifestyle in order to survive, faking it without an internalised alternative consciousness.

Spaces are created in the community, such as induction workshops for new staff members and volunteers or interns, as well as discipleship and healing workshops, in which prejudice is dealt with among other things. But ultimately it is up to every individual to decide how they will engage 'the other'. 
Naming prejudice is both personal and political. The banner 'welcoming strangers, welcoming Jesus' - was in response to xenophobic attacks against foreign nationals. An embrace of diversity is not simply a 'soft' or 'warm' gesture but at the same time practising a politics of justice. In one case the Department of Social Development wanted to require of TLF to stop employing a staff member who was inter-sexual because they would not fund this person's salary. TLF was able to resist.

The issue of homeless people dying with terminal illnesses on the streets of the city, or of young girls being trafficked for commercial sex work, is deeply a personal and pastoral concern but at the same time a socio-political concern.

Although the issues that TLF engages with tend to be highly political - spatial justice, housing, homelessness, gender justice, human trafficking - TLF discourages its members to use TLF spaces to promote their own political parties. It can probably be said that what TLF practices is a faith-based, faith-informed, non-partisan politics.

\section{Nurturing spirituality}

It is said by De Beer (2016) that TLF is developing an own spirituality, in diversity, whilst remaining 'open to hear from others and to see how others live their faith'. In the chaos of diversity, TLF introduced the discipline of spiritual practices, overseen by a Spirituality Committee. Part of the function of this committee is to protect the rights of the vulnerable communities we serve, to not be indoctrinated and targeted for evangelization purposes'.

Nurturing spirituality is central to the pastoral responsibilities of TLF, ensuring for example 'that community members are in solid faith programmes', that they are encouraged to participate in a church of their choice and 'that pastoral counselling is received when necessary'. Therefore, TLF also ensures that not any faith community can enter into any of the TLF-aligned communities freely, to offer spiritual or pastoral services in whichever they want. Instead, TLF would rather take time 'to build relationships of trust with other faith communities slowly and to allow inputs from others in a careful way' (as shared by the leader of the organisation).

Spirituality seems to be at the core of collective discernment and decision-making in TLF. Again, Ascough's reflections on Paul's leadership in relation to chaos theory strike a chord. Ascough (2002:26) suggests that Paul's approach to the church in Corinth was not to 'lay down a single, simple rule to govern all situations. Instead, he offers a principle ...'. It seems, according to Ascough, as if Paul's leadership asserted the principle that '(n)o external rules are needed, since Christians have the Spirit dwelling in them to provide guidance in how they live'.

There is also sensitivity in TLF for the reality that community members come from different backgrounds, often rooted in their own spiritualities. Spaces are created to learn from different spirituality, to allow for a fusion of spiritualities and even to create spaces which 'God can use to meet us differently' and in and with our difference. These are spaces which are, again, comfortable with paradox, chaos and uncertainty, dancing together with each other and the Spirit, allowing for chaordic beauty to unfold.

\section{Conclusion}

In this article I sought to describe the diversity of one inner city faith community and reflected with some of their members on ways in which they dealt with their diversity. In their own language they spoke of embracing strangers, offering warm hospitality and welcoming everyone at the same table.

In engaging and inviting difference and otherness hospitably, with the multiple narratives such difference represents, I gathered that this faith community is being uniquely storied, discovering in its dance with chaos, and its celebration of diversity, the unfolding of chaordic beauty: surprisingly tall and alternative narratives to the dominant narratives about diversity, difference and the other (cf. Boomkens 1998).

Instead of the conventional emphasis on the management of diversity, or controlling chaos, a chaordic spirituality (embracing chaos, disciplined dancing, vulnerable connectedness) seems to sustain TLF's organisational posture and leadership approach, which is to embrace and enjoy chaos and its hidden beauties and potentials, dancing out of control and into a new order.

\section{Acknowledgements Competing interests}

The author declares that he has no financial or personal relationships which may have inappropriately influenced him in writing this article.

\section{References}

Ascough, R., 2002, 'Chaos theory and Paul's organizational leadership style', Journal of Religious Leadership1(2Fall), 21-43.

Boomkens, R., 1998, Een drempelwêreld,NAi Uitgevers, Rotterdam.

De Beer, S., 2008, 'Contesting inner-city space: Global trends, local exclusion/s and an alternative Christian spatial praxis', Missionalia 36(2/3), 181-207.

De Beer, S. \& De Beer, W., 2002, 'Journeying on the margins. Moments inpastoral care and counselling, from the inner city of Pretoria', in J.R. Farris (ed.), International perspectives on pastoral counselling, pp. 253-294, Routledge, New York.

Feast of the Clowns, 2016, viewed 11 May 2016, from http://feast.tlf.org.za/

Hillis, D., 2014, Cities: Playgrounds or battlegrounds, Leadership Foundations Press, Tacoma, WA.

Hjalmarson, L., 2013, Leadership in the chaordic age, viewed 6 February 2016, from http://nextreformation.com/wp-content/uploads/2013/05/Leadership_in_ Chaordic_Age.pdf

Hock, D.W., 1999, Birth of the chaordic age, Brett-Koehler Publishers, Inc., San-Francisco, CA.

Hock, D.W., n.d., The chaordic organization: Out of control and into order, viewed 6 February 2016, from http://www.ratical.org/many_worlds/ChaordicOrg.pdf

Kurtz, E. \& Ketcham, K., 1993, The spirituality of imperfection: Storytelling and the search for meaning, Bantam, New York.

Motumura, O., n.d., Chaordicorganizations, viewed 25 March 2016, from http://www. paricenter.com/library/papers/Chaordic_organizations.pdf

Searcy, N. \& Hall, C., 2000, 'An interview with Dee Hock', Smart Leadership Magazine, April, viewed 5 May 2016, from http://www.smartleadership.com/ articles/hock.html 
Tetenbaum, T., 1998, 'Shifting paradigms: From Newton to chaos', Organizational Dynamics 15(Spring), 21.

Tshwane Leadership Foundation, 2016, viewed 6 May 2016, from http://www.tlf.org.za Volf, M., 1996, Exclusion and embrace: A theological exploration of identity, otherness, and reconciliation, Abingdon Press, Nashville, TN.

Wheatley, M., 1992, Leadership and the new science: Learning about organization from an orderly universe, Berret-Koehler, San Francisco, CA.
Wheatley, M., 2006, Leadership lessons from the real world, viewed 16 February 2016, from http://www.margaretwheatley.com/articles/unplannedorganization. html

Wheatley, M., 2007a, The unplanned organization: Learning from nature's emergent creativity, viewed 16 February 2016, from http://www.margaretwheatley.com/ articles/unplannedorganization.html

Wheatley, M., 2007b, Finding our way again: Leadership for an uncertain time, Barrett Koehler, San Francisco, CA. 